- Original Article

\title{
The Effect of Continuous Care Model Implementation on the Quality of Life of Patients with Heart Failure: $A$ Randomized Controlled Trial
}

\author{
Fatemeh Rezamand', Hossein Shahnazi ${ }^{2, *}$, Akbar Hassanzadeh $^{3}$ \\ 'Student Research Committee, School of Health, Isfahan University of Medical Sciences, Isfahan, Iran \\ ${ }^{2}$ Department of Health Education and Promotion, School of Health, Isfahan University of Medical Sciences, Isfahan, Iran \\ ${ }^{3}$ Department of Epidemiology and Biostatistics, School of Health, Isfahan University of Medical Sciences, Isfahan, Iran
}

Background: Heart failure is an important chronic and progressive disease worldwide. Patients are faced with several stressors that decrease their quality of life (QoL). The present study aimed to determine the effectiveness of implementing a continuous care model on improving the QoL of patients with heart failure.

Methods: In the present randomized controlled trial, 72 patients with heart failure admitted to Shahid Chamran Hospital of Isfahan (in Central Iran) were randomly divided into 36-individual two groups: the experimental (continuous care model) and control (normal care) groups. In the experimental group, the continuous care model was implemented for 3 months. Data were collected using the standard Minnesota Living with Heart Failure Questionnaire for patients with heart failure. Subsequently, the collected data were entered into the IBM SPSS ver. 20.0 (IBM Corp., Armonk, NY, USA) and analyzed using the Mann-Whitney U-test, chi-square test, and independent and paired t-test at a significance level of $\alpha \leq 0.05$.

Results: The results indicated that the mean scores of QoL before the implementation of continuous care model were $43.3 \pm 6.1$ in the experimental group and $42.7 \pm 5.1$ in the control group, indicating no statistically significant difference between the two groups. After the implementation of continuous care model, the mean score of QoL of the experimental group was significantly higher than that of the control group.

Conclusion: Considering the results obtained in the present study, model implementation could improve the overall scores of QoL in patients with chronic heart failure.

Keywords: Heart Failure; Quality of Life; Critical Care; Patients

Received: March 6, 2020, Revised: April 1, 2020, Accepted: April 2, 2020

${ }^{*}$ Corresponding Author: Hossein Shahnazi https://orcid.org/0000-0002-5901-3901

Tel: +98-3137923243, Fax: +98-3136682509, E-mail: h_shahnazi@hlth.mui.ac.ir 


\section{INTRODUCTION}

Cardiovascular diseases are the number one cause of death in people aged $>35$ years in Iran. ${ }^{1)}$ According to the Center for Disease Control and Prevention statistics in Iran, approximately 3,400 per 100,000 individuals are diagnosed with heart failure in Iran, and these individuals experience the debilitating complications of heart failure. ${ }^{2)}$ Heart failure is a widely common cause of early hospitalization and readmission in patients aged $>65$ years. ${ }^{3)}$ There are no specific statistics on the prevalence of cardiovascular diseases in Iran, but mortality from heart disease has increased by approximately $20 \%$ to $45 \%$ according to several studies in Iran. ${ }^{4)}$ The incidence and increased mortality rates of heart failure are directly associated with increasing age, that is, for every 10 -year increase in age, the risk of heart failure doubles. ${ }^{5,6)}$ Generally, the number of individuals diagnosed with heart failure is expected to increase as the population ages and as survival rate improves. ${ }^{7)}$

Previous studies have found that the quality of life of patients with heart failure is lower than that of the general population and other chronic patients. ${ }^{8)}$ In fact, quality of life is an index that is increasingly used as an endpoint of health interventions for patients with heart failure. $^{9)}$

According to previous studies assessing the quality of life of patients with heart failure, the quality of life of patients diagnosed with heart failure has been impaired in several aspects as follows: (1) physical health: including pain and discomfort, sleep and rest, and the ability to perform work and daily activities; (2) psychological (emotional) aspects: including appearance, positive and negative emotions, selfconfidence, memory, and concentration; (3) social relations (public): including personal relations, sexual activities, and social support; and (4) social environment: including home financing, access to information, participation in social activities, and commuting facilities. ${ }^{10)}$

Several studies have examined the impact of scheduled telephone follow-up in patients with heart failure. ${ }^{11-13)}$ According to a previous research comprising 14 studies on telephone interventions in heart failure, Clark et al. ${ }^{14)}$ found a $21 \%$ overall reduction in readmission and a $20 \%$ reduction in patient mortality rates and reported the benefits of such interventions on patients' quality of life and reduction of costs. In this regard, a model, called continuous care model, was initially introduced by Abedi et al. ${ }^{15)}$ in 2005 in Iran for the care and follow-up of chronic coronary patients. The use of this model affects several factors such as number of hospitalizations, frequency of visits to physicians, blood lipid levels, dietary modifications, and frequency of using sublingual tablets (nitroglycerin), specifically the quality of life of chronic coronary patients. ${ }^{15)}$ Healthcare providers should encourage patients with heart failure to adjust and achieve their goals such as stress reduction, proper medication use, fluid restriction, proper diet, and exercise programs. ${ }^{16)}$ The main purpose of this model is to design and develop a program to increase knowledge, attitude, and proper performance of patient care to prevent the development or the potential complications of the disease. ${ }^{17)}$

The continuous care model comprises the following four steps: (1) orientation, (2) sensitization, (3) control, and (4) evaluation. The purposes of the orientation phase are to identify the interactions of patient, family, and educator, provide proper explanation of the problem to the patients, motivate patients, create a sense of need, and explain the whole process. The sensitization phase aims to engage patients and their families in implementing a continuous care approach. At this stage, if patients and their families have the necessary knowledge about problem identification and sensitivity, we can expect that these patients will enjoy a higher quality of life than before. The aim of the sensitization phase is to understand the nature of heart failure as much as patients' perception, the importance of following medication, the limitations for patients and their families, and the importance of physical activity. The goal control phase aims to continue the process of implementing a continuous care model because the best programs lose their desired impact over time without follow-up. The evaluation is the fourth and final step of the continuous care model, but this step should be taken into consideration at all stages of model implementation. The overall goal of this phase is to examine the continuous care process during the intervention.

Considering that the continuous care model has been used in chronic diseases such as diabetes and dialysis, and their results indicate the impact of this model on improving the quality of life in these patients and considering the significantly low statistics of continuous care in improving the quality of life of patients with heart failure, the present study aimed to determine the impact of implementing a continuous care model on improving the quality of life of patients with heart failure in controlling disease complications.

\section{METHODS}

\section{Study Design and Sampling}

In this parallel-group, randomized controlled trial, the statistical population comprised patients who had been admitted to Shahid Chamran Heart Hospital of Isfahan and who were diagnosed with heart failure by cardiologists in 2018 .

A total of 72 patients who were eligible to participate in the study based on the inclusion criteria were randomly selected as samples by systematic random sampling from files of patients with heart failure in medical archives and records of hospital with the history of referral and admission to the hospital during the past 6 months. Study participants were randomly allocated to the experimental or control groups using a computer-generated randomization sequence obtained by a third party (independent of the research team) and concealed from the research team until patients were allocated to the study groups. The allocation ratio was 1:1. The required sample size for each group was 32, which was based on the findings of a study conducted by Harrison et al., ${ }^{18)}$ and a standard error of $5 \%$ and a test power of $90 \%$ were considered. The final sample size was estimated to be 36 per group with $12 \%$ drop of samples. According to the collected data from hospital's archives and medical records and contact phone numbers in patients' files, written invitations were created and sent to the partici- 
pants who were eligible to participate in the study.

These participants were subsequently examined in terms of inclusion criteria and randomly divided into two 36-individual experimental and control groups.

The inclusion criteria were as follows: age less than 80 years, consent to participate in the study, at least having a primary school degree, definitive diagnosis of heart failure at least 6 months before the study, and absence of cardiac surgery history.

The exclusion criteria were as follows: failure to attend training sessions, any conditions that did not meet the inclusion criteria (such as undergoing cardiac surgery or a patient diagnosed with myocardial infarction), patients who were not allowed to perform physical activities, and patients who were following a special diet.

\section{Ethics Approval}

All patients provided written informed consent. The questionnaires were completed without mentioning patients' names and characteristics, and they were assured of the confidentiality of their information. The present study was derived from the research design no. 396696 approved by the deputy of research at Isfahan University of Medical Sciences with Code of Ethics of IR.MUI.REC.1396.3.696.

\section{Data Collection Tool}

Data collection tool included the demographic questionnaire and the Minnesota Living with Heart Failure Questionnaire (MLHFQ). The Minnesota questionnaire comprised 21 questions about physical, emotional, and general domains, and each question had six criteria that were scored from 0 to 5 . Number 0 represented the best state, and 5 represented the worst state. ${ }^{19)}$

The MLHFQ was validated in a study by Rector and Cohn. ${ }^{20)}$ Content validity was used to determine the scientific validity of the questionnaire. Test-retest method was used to determine the reliability of tool; hence, the questionnaire was completed by 36 patients and subsequently recompleted a week later. Finally, the reliability of questionnaire was confirmed with the correlation coefficient of $\alpha=91 \%$ and $\alpha=81 \%$.

\section{Intervention}

The intervention comprised four training sessions, each of which was performed for an hour for the experimental group in the training hall of Shahid Chamran Heart Hospital of Isfahan. During the training sessions, patients were taught about understanding the disease process, the importance of treatment process, medication and drug use introduction, drug use method and its side effects, familiarity with disease symptoms, likelihood of problems during sleeping, the way of dealing with problems in communicating with friends and family members, problems with daily activities, training to overcome anxiety and depression, patient response to shortness of breath, coping with sense of living off the family, and distraction and reminding general content and education in booklet and pamphlets (Table 1).

The continuous care model was implemented on the experimental group; subsequently, follow-ups and sending messages were performed weekly for 3 months. A 10-minute phone call per week was made with each patient. It should be noted that the duration of calls might vary according to the needs and educational questions of each patient. In general, 12 calls were made with each patient within 3 months. Two messages per week were sent to each patient or one of their family members, and a total of 24 text messages were sent for each patient. The written schedule of calls during the training sessions was provided to patients and their companions. The educational content during telephone conversations included the content in training sessions and educational booklets, answering patient questions or their companions, examining reasons for patients' noncompliance with points in training sessions, and providing solutions to patients for

Table 1. Summary of goals and strategies of training sessions

\begin{tabular}{|c|c|c|c|}
\hline No. & Behavioral goals & Domain & Educational strategy \\
\hline 1 & Patients can have a complete definition of heart failure. & Cognitive & Lecture-questions and answers-pamphlets-educational booklet \\
\hline 2 & Patients can explain the causes of disease and symptoms of heart failure. & Cognitive & Lecture-questions and answers-pamphlets-educational booklet \\
\hline 3 & $\begin{array}{l}\text { Patients can have a full definition of the concept of quality of life in heart } \\
\text { failure. }\end{array}$ & Cognitive & Lecture-questions and answers \\
\hline 4 & Patients can assess the quality of life in four aspects. & Cognitive-affective & Lecture-questions and answers-pamphlets-educational booklet \\
\hline 5 & $\begin{array}{l}\text { Patients can understand and respond to the concept of quality of life in } \\
\text { improving disease. }\end{array}$ & Cognitive-affective & Lecture-questions and answers \\
\hline 6 & $\begin{array}{l}\text { Patients understand the importance of drug therapy and appropriate use } \\
\text { of medications. }\end{array}$ & Affective & Educational booklet \\
\hline 7 & $\begin{array}{l}\text { Patients can express ways to improve the quality of life of patients with } \\
\text { heart failure. }\end{array}$ & Cognitive & Educational booklet \\
\hline 8 & Patients are able to perform daily physical activities. & Psychomotor & Educational booklet \\
\hline 9 & $\begin{array}{l}\text { Patients are able to resolve problems in relationship with friends and } \\
\text { family members. }\end{array}$ & Psychomotor & Educational booklet \\
\hline 10 & Patients can overcome their anxiety and sense of living off family. & Psychomotor & Educational booklet-role-playing \\
\hline 11 & Patients can positively respond to shortness of breath. & Psychomotor & Educational booklet-role-playing \\
\hline 12 & Patients can express ways to deal with anxiety and depression. & Cognitive & Lecture-questions and answers-pamphlets-educational booklet \\
\hline 13 & Patients become familiar with types of phone calls and training. & Cognitive & Lecture-questions and answers-pamphlets-educational booklet \\
\hline 14 & Patients can ask their questions from their educators through phone calls. & Psychomotor & Lecture-questions and answers-pamphlets-educational booklet \\
\hline
\end{tabular}


problem-solving. Patients and their companions could also contact a telephone number that was provided by the researcher for 24 hours per day if any problem or question was noted. All calls were made by the researcher to track patients. Finally, the questionnaires were recompleted for both groups 3 months after the intervention.

In the present study, four stages of continuous care model were conducted for patients: orientation, sensitization, control, and evaluation.

\section{1) Orientation}

This stage aimed to introduce the researcher, patient, and a member of the patient's family involved in the continuous care for patient and identify research goals, possibilities, limitations, and expectations. In fact, this stage was the beginning of engaging patients and their families to improve their quality of life. Therefore, a training session was held for 60 minutes. They also explained how to contact the researcher by providing contact numbers to patients and their companions. At this stage, written consent forms and quality of life questionnaires were completed by the patients in the intervention group.

\section{2) Sensitization}

Sensitization was performed to engage patients and their families to improve their quality of life, which was simultaneously performed at the beginning of the orientation phase. Care counseling was an important measure for patients with heart failure at this stage. Hence, patients in the experimental group with one of their closest family members participated in four training sessions in the training hall of Chamran Hospital. Care process and the disease course were also reviewed in this stage. The training sessions comprised questions and answers (at the beginning of the session) followed by the researcher's presentation with the aid of slides and lectures. The educational content was re-explained, if necessary, until problems were resolved and patients achieved full learning. At the end of each training session, educational booklets and pamphlets were provided to the patients.

\section{3) Control}

During this stage, patients' behaviors and their quality of life were con-

Table 2. Frequency distribution of patients' sex, marital status, and educational levels between the two groups

\begin{tabular}{lrrr}
\hline \multicolumn{1}{c}{ Variable } & Experimental group & Control group & P-value \\
\hline Sex & & & $0.19^{\star}$ \\
Male & $28(77.8)$ & $23(63.9)$ & \\
$\quad$ Female & $8(22.2)$ & $13(36.1)$ & \\
Marital status & & & $0.10^{\star}$ \\
$\quad$ Married & $33(91.7)$ & $28(77.8)$ & \\
$\quad$ Single & $3(8.3)$ & $8(22.2)$ & \\
Educational level & & & $0.71^{\dagger}$ \\
$\quad$ Primary school & $5(13.9)$ & $5(13.9)$ & \\
Secondary school & $8(22.2)$ & $11(30.5)$ & \\
$\quad$ High school diploma & $13(36.1)$ & $10(27.8)$ & \\
$\quad$ Academic & $10(27.8)$ & $10(27.8)$ & \\
\hline
\end{tabular}

Values are presented as number (\%).

*By chi-square test. 'By Mann-Whitney U-test. trolled during 12 phone calls per patient over a period of 3 months according to provided training and their application by patients.

\section{4) Evaluation}

Finally, the success of the intervention was evaluated using a questionnaire to measure and compare the Minnesota's quality of life dimensions.

In this study, the control group received only the routine care, which comprises education delivered by nurses during hospitalization. These are only general training according to rehabilitation guidelines.

\section{Data Analysis}

The collected data were entered into the IBM SPSS ver. 20.0 (IBM Corp., Armonk, NY, USA). Chi-square test, Mann-Whitney U-test, and independent and paired t-tests were examined with a significant level of $\alpha \leq 0.05$. Chi-square test was used to compare two groups in terms of sex and marital status. Mann-Whitney U-test was also utilized to compare the educational level between the experimental and control groups. Independent t-test was used to compare the mean scores of quality of life in two groups at two studied times (before and 3 months after training). Paired t-test was utilized to compare the mean scores of quality of life in each group before and after the intervention.

\section{RESULTS}

In the present study, the mean ages of the patients were $59.1 \pm 11.9$ years in the experimental group and $62.5 \pm 11.1$ years in the control group. The independent t-test indicated that there was no significant difference between both groups in terms of mean age $(\mathrm{P}=0.21)$.

The majority of patients were male $(77.8 \%$ in the experimental group and $63.9 \%$ in the control group). Chi-square test indicated that

Table 3. Comparison of the mean scores of quality of life dimensions before and 3 months after the continuous care model implementation in the experimental and control groups

\begin{tabular}{lccc}
\hline Quality of life dimensions & Pre-intervention & Post-intervention & P-value $^{*}$ \\
\hline Physical dimension & & & \\
Experimental & $50.2 \pm 5.3$ & $65.5 \pm 5.3$ & $<0.001$ \\
Control & $48.9 \pm 5.1$ & $49.1 \pm 8.2$ & 0.89 \\
P-value $^{\dagger}$ & 0.28 & $<0.001$ & - \\
Emotional dimension $_{\text {Experimental }}$ & $28 \pm 10.6$ & $49 \pm 6.9$ & $<0.001$ \\
Control $^{\text {P-value }}{ }^{\dagger}$ & $27 \pm 6.9$ & $29.4 \pm 10.7$ & 0.28 \\
General dimension $^{\text {Experimental }}$ & 0.64 & $<0.001$ & - \\
Control $^{\text {P-value }}{ }^{\dagger}$ & $45.4 \pm 9.9$ & $58.4 \pm 5.9$ & $<0.001$ \\
Total $_{\text {Experimental }}$ & $45.9 \pm 8.5$ & $47.02 \pm 8.4$ & 0.57 \\
Control $_{\text {P-value }}^{\dagger}$ & 0.80 & $<0.001$ & - \\
\hline
\end{tabular}

Values are presented as mean \pm standard deviation, unless otherwise stated. *By paired t-test. ${ }^{\dagger}$ By independent t-test. 
Table 4. Frequency distribution of response to questions of quality of life questionnaire in pre-and post-intervention

\begin{tabular}{|c|c|c|c|c|c|c|c|}
\hline Question & Category & 0 & 1 & 2 & 3 & 4 & 5 \\
\hline \multirow{4}{*}{$\begin{array}{l}\text { 1. Does the disease cause edema in lower } \\
\text { extremities? }\end{array}$} & Control pre-intervention & $21(58.3)$ & $15(41.7)$ & 0 & 0 & 0 & 0 \\
\hline & Control post-intervention & 28 (77.8) & $8(22.2)$ & 0 & 0 & 0 & 0 \\
\hline & Experimental pre-intervention & $18(50)$ & $17(47.2)$ & 0 & $1(2.8)$ & 0 & 0 \\
\hline & Experimental post-intervention & $29(80.6)$ & $6(16.7)$ & 0 & $1(2.8)$ & 0 & 0 \\
\hline \multirow{4}{*}{$\begin{array}{l}\text { 2. Does the disease force you to sit during the } \\
\text { day? }\end{array}$} & Control pre-intervention & 0 & $2(5.6)$ & $20(55.6)$ & 12 (33.2) & $2(5.6)$ & 0 \\
\hline & Control post-intervention & 0 & $11(30.6)$ & $20(55.6)$ & $5(13.9)$ & 0 & 0 \\
\hline & Experimental pre-intervention & 0 & $3(8.3)$ & $17(47.2)$ & $15(41.7)$ & $1(2.8)$ & 0 \\
\hline & Experimental post-intervention & 0 & $20(55.6)$ & $15(41.7)$ & $1(2.8)$ & 0 & 0 \\
\hline \multirow{4}{*}{$\begin{array}{l}\text { 3. Does the disease make going upstairs and } \\
\text { downstairs difficult for you? }\end{array}$} & Control pre-intervention & 0 & 0 & $2(5.6)$ & $28(77.8)$ & $6(16.7)$ & 0 \\
\hline & Control post-intervention & 0 & $3(8.3)$ & $18(50)$ & $13(36.1)$ & $2(5.6)$ & 0 \\
\hline & Experimental pre-intervention & 0 & 0 & $6(16.7)$ & $23(63.9)$ & $7(19.4)$ & 0 \\
\hline & Experimental post-intervention & 0 & $11(30.6)$ & $23(63.9)$ & $2(5.6)$ & 0 & 0 \\
\hline \multirow{4}{*}{$\begin{array}{l}\text { 4. Does the disease make working at home } \\
\text { difficult for you? }\end{array}$} & Control pre-intervention & 0 & 0 & $5(13.9)$ & 30 (83.3) & $1(2.8)$ & 0 \\
\hline & Control post-intervention & 0 & $7(19.4)$ & $15(41.7)$ & 14 (38.9) & 0 & 0 \\
\hline & Experimental pre-intervention & 0 & 0 & $9(25)$ & $24(66.7)$ & $3(8.3)$ & 0 \\
\hline & Experimental post-intervention & 0 & $20(55.6)$ & $14(38.9)$ & $2(5.6)$ & 0 & 0 \\
\hline \multirow{4}{*}{$\begin{array}{l}\text { 5. Does the disease make walking far from } \\
\text { home difficult for you? }\end{array}$} & Control pre-intervention & 0 & $9(25)$ & $24(58.5)$ & $2(5.6)$ & $1(2.8)$ & 0 \\
\hline & Control post-intervention & $7(19.4)$ & $20(55.6)$ & $9(25)$ & 0 & 0 & 0 \\
\hline & Experimental pre-intervention & $5(13.9)$ & $11(30.6)$ & $17(47.2)$ & $3(8.3)$ & 0 & 0 \\
\hline & Experimental post-intervention & 19 (52.8) & $17(47.2)$ & 0 & 0 & 0 & 0 \\
\hline \multirow{4}{*}{$\begin{array}{l}\text { 6. Does the disease make sleeping difficult } \\
\text { for you? }\end{array}$} & Control pre-intervention & 0 & $3(8.3)$ & $27(75)$ & $6(16.7)$ & 0 & 0 \\
\hline & Control post-intervention & 0 & $5(13.9)$ & $29(80.6)$ & $2(5.6)$ & 0 & 0 \\
\hline & Experimental pre-intervention & 0 & $1(2.8)$ & $30(83.3)$ & $5(13.9)$ & 0 & 0 \\
\hline & Experimental post-intervention & 0 & $10(27.8)$ & $26(72.2)$ & 0 & 0 & 0 \\
\hline \multirow{4}{*}{$\begin{array}{l}\text { 7. Does the disease make relationships with } \\
\text { friends and family members difficult for } \\
\text { you? }\end{array}$} & Control pre-intervention & 0 & 0 & $2(5.6)$ & 30 (83.3) & $4(11.1)$ & 0 \\
\hline & Control post-intervention & 0 & 0 & $16(44.4)$ & 19 (52.8) & $1(2.8)$ & 0 \\
\hline & Experimental pre-intervention & 0 & 0 & $3(8.3)$ & $22(61.1)$ & $11(30.6)$ & 0 \\
\hline & Experimental post-intervention & 0 & 0 & $21(58.3)$ & $15(41.7)$ & 0 & 0 \\
\hline \multirow{4}{*}{$\begin{array}{l}\text { 8. Does the disease make daily activities } \\
\text { difficult for you? }\end{array}$} & Control pre-intervention & 0 & 0 & $13(36.1)$ & 23 (63.9) & 0 & 0 \\
\hline & Control post-intervention & 0 & 0 & $2(5.6)$ & $33(91.7)$ & $1(2.8)$ & 0 \\
\hline & Experimental pre-intervention & 0 & 0 & $14(38.9)$ & $22(61.1)$ & 0 & 0 \\
\hline & Experimental post-intervention & 0 & 0 & 0 & $31(86.1)$ & $5(13.9)$ & 0 \\
\hline \multirow{4}{*}{$\begin{array}{l}\text { 9. Does the disease make exercise, physical } \\
\text { activity, and recreationdifficult for you? }\end{array}$} & Control pre-intervention & 0 & 0 & $1(2.8)$ & $19(52.8)$ & $16(44.4)$ & 0 \\
\hline & Control post-intervention & 0 & 0 & $3(8.3)$ & $27(75)$ & $6(16.7)$ & 0 \\
\hline & Experimental pre-intervention & 0 & 0 & 0 & $15(41.7)$ & $21(58.3)$ & 0 \\
\hline & Experimental post-intervention & 0 & 0 & $7(19.4)$ & 29 (80.6) & 0 & 0 \\
\hline \multirow{4}{*}{$\begin{array}{l}\text { 10. Does the disease make you unable to do } \\
\text { your job? }\end{array}$} & Control pre-intervention & 0 & 0 & $2(5.6)$ & 23 (63.9) & $11(30.6)$ & 0 \\
\hline & Control post-intervention & 0 & 0 & $9(25)$ & $23(63.9)$ & $4(11.1)$ & 0 \\
\hline & Experimental pre-intervention & 0 & 0 & $5(13.9)$ & $17(47.2)$ & $13(36.1)$ & $1(2.8)$ \\
\hline & Experimental post-intervention & 0 & 0 & $23(63.9)$ & $13(36.1)$ & 0 & 0 \\
\hline \multirow{4}{*}{$\begin{array}{l}\text { 11. Does the disease make sexual activities } \\
\text { difficult for you? }\end{array}$} & Control pre-intervention & 0 & 0 & 0 & $17(47.2)$ & $19(52.8)$ & 0 \\
\hline & Control post-intervention & 0 & 0 & $9(25)$ & $19(52.8)$ & $8(22.2)$ & 0 \\
\hline & Experimental pre-intervention & 0 & 0 & $6(16.7)$ & $12(33.3)$ & $17(47.2)$ & $1(2.8)$ \\
\hline & Experimental post-intervention & 0 & 0 & $15(41.7)$ & $19(52.8)$ & $2(5.6)$ & 0 \\
\hline
\end{tabular}


Table 4. Continued

\begin{tabular}{|c|c|c|c|c|c|c|c|}
\hline Question & Category & 0 & 1 & 2 & 3 & 4 & 5 \\
\hline \multirow{4}{*}{$\begin{array}{l}\text { 12. Does the disease make you eat less of } \\
\text { your favorite food? }\end{array}$} & Control pre-intervention & 0 & 0 & 0 & 0 & $25(69.4)$ & $11(30.6)$ \\
\hline & Control post-intervention & 0 & 0 & 0 & $9(25)$ & $25(69.4)$ & $2(5.6)$ \\
\hline & Experimental pre-intervention & 0 & 0 & 0 & 0 & $26(72.2)$ & $10(27.8)$ \\
\hline & Experimental post-intervention & 0 & 0 & 0 & $14(38.9)$ & $22(61.1)$ & 0 \\
\hline \multirow{4}{*}{$\begin{array}{l}\text { 13. Does the disease cause shortness of } \\
\text { breath in you? }\end{array}$} & Control pre-intervention & 0 & $1(2.8)$ & $25(69.4)$ & $8(22.2)$ & $2(5.6)$ & 0 \\
\hline & Control post-intervention & 0 & $13(36.1)$ & $20(55.6)$ & $2(5.6)$ & $1(2.8)$ & 0 \\
\hline & Experimental pre-intervention & 0 & $6(16.7)$ & $21(58.3)$ & $9(25)$ & 0 & 0 \\
\hline & Experimental post-intervention & 0 & $27(75)$ & $9(25)$ & 0 & 0 & 0 \\
\hline \multirow{4}{*}{$\begin{array}{l}\text { 14. Does the disease cause fatigue or loss of } \\
\text { energy in you? }\end{array}$} & Control pre-intervention & 0 & 0 & 0 & $3(8.3)$ & $32(88.9)$ & $1(2.8)$ \\
\hline & Control post-intervention & 0 & 0 & $3(8.3)$ & $18(50)$ & $15(41.7)$ & 0 \\
\hline & Experimental pre-intervention & 0 & 0 & 0 & $7(19.4)$ & $29(80.6)$ & 0 \\
\hline & Experimental post-intervention & 0 & 0 & $6(16.7)$ & $29(80.6)$ & $1(2.8)$ & 0 \\
\hline \multirow{4}{*}{$\begin{array}{l}\text { 15. Has the disease ever caused your } \\
\text { hospitalization? }\end{array}$} & Control pre-intervention & 0 & $19(52.8)$ & $14(38.9)$ & $2(5.6)$ & $1(2.8)$ & 0 \\
\hline & Control post-intervention & 0 & $28(77.8)$ & $7(19.4)$ & $1(2.8)$ & 0 & 0 \\
\hline & Experimental pre-intervention & 0 & $22(61.1)$ & $13(36.1)$ & $1(2.8)$ & 0 & 0 \\
\hline & Experimental post-intervention & 0 & $36(100)$ & 0 & 0 & 0 & 0 \\
\hline \multirow{4}{*}{$\begin{array}{l}\text { 16. Has the payment of medical treatment } \\
\text { costs caused problems for your life? }\end{array}$} & Control pre-intervention & 0 & 0 & 0 & $1(2.8)$ & $20(55.6)$ & $15(41.7)$ \\
\hline & Control post-intervention & 0 & 0 & 0 & $11(30.6)$ & $20(55.6)$ & $5(13.9)$ \\
\hline & Experimental pre-intervention & 0 & 0 & 0 & $1(2.8)$ & $19(52.8)$ & $16(44.4)$ \\
\hline & Experimental post-intervention & 0 & 0 & 0 & $22(61.1)$ & $14(38.9)$ & 0 \\
\hline \multirow{4}{*}{$\begin{array}{l}\text { 17. Do medications for treating the heart } \\
\text { failure lead to side effects for you? }\end{array}$} & Control pre-intervention & $2(5.6)$ & $18(50)$ & $12(33.3)$ & $1(2.8)$ & $3(8.3)$ & 0 \\
\hline & Control post-intervention & $1(2.8)$ & $15(41.7)$ & $19(52.8)$ & 0 & $1(2.8)$ & 0 \\
\hline & Experimental pre-intervention & $1(2.8)$ & $17(47.2)$ & $12(33.3)$ & 0 & $6(16.7)$ & 0 \\
\hline & Experimental post-intervention & $2(5.6)$ & $20(55.6)$ & $12(33.3)$ & $2(5.6)$ & 0 & 0 \\
\hline \multirow{4}{*}{$\begin{array}{l}\text { 18. Does the disease make the sense of living } \\
\text { off the family in you? }\end{array}$} & Control pre-intervention & 0 & & $1(2.8)$ & $11(30.6)$ & $23(63.9)$ & $1(2.8)$ \\
\hline & Control post-intervention & 0 & & $4(11.1)$ & $22(61.1)$ & $10(27.8)$ & 0 \\
\hline & Experimental pre-intervention & 0 & & 0 & $15(41.7)$ & $21(58.3)$ & 0 \\
\hline & Experimental post-intervention & 0 & & $4(11.1)$ & $30(83.3)$ & $2(5.6)$ & 0 \\
\hline \multirow[t]{4}{*}{ 19. Does the disease make you feel anxious? } & Control pre-intervention & 0 & & 0 & $2(5.6)$ & $28(77.8)$ & $6(16.7)$ \\
\hline & Control post-intervention & 0 & $1(2.8)$ & $9(25)$ & $16(44.4)$ & $9(25)$ & $1(2.8)$ \\
\hline & Experimental pre-intervention & 0 & 0 & 0 & $5(13.9)$ & $27(75)$ & $4(11.1)$ \\
\hline & Experimental post-intervention & 0 & $1(2.8)$ & $18(50)$ & $16(44.4)$ & $1(2.8)$ & 0 \\
\hline \multirow{4}{*}{$\begin{array}{l}\text { 20. Does the disease cause distraction and } \\
\text { content reminding in you? }\end{array}$} & Control pre-intervention & $8(22.2)$ & $11(30.6)$ & $8(22.2)$ & $1(2.8)$ & $8(42.1)$ & 0 \\
\hline & Control post-intervention & $11(30.6)$ & $11(30.6)$ & $12(33.3)$ & 0 & $2(5.6)$ & 0 \\
\hline & Experimental pre-intervention & $11(30.6)$ & $7(19.4)$ & $7(19.4)$ & 0 & $11(30.6)$ & 0 \\
\hline & Experimental post-intervention & $12(33.3)$ & $13(36.1)$ & $7(19.7)$ & $4(11.1)$ & 0 & 0 \\
\hline \multirow{4}{*}{$\begin{array}{l}\text { 21. Does the disease make you feel } \\
\text { depressed? }\end{array}$} & Control pre-intervention & 0 & 0 & $1(2.8)$ & $8(22.2)$ & $21(58.3)$ & $6(16.7)$ \\
\hline & Control post-intervention & 0 & 0 & 20 (55.6) & $9(25)$ & $6(16.7)$ & $1(2.8)$ \\
\hline & Experimental pre-intervention & 0 & 0 & $3(8.3)$ & $7(19.4)$ & $18(50)$ & $8(22.2)$ \\
\hline & Experimental post-intervention & 0 & 0 & $27(75)$ & 8 (22.2) & $1(2.8)$ & 0 \\
\hline
\end{tabular}

Values are presented as number (\%).

the frequency distribution of $\operatorname{sex}(\mathrm{P}=0.19)$ and marital status $(\mathrm{P}=0.10)$ had no significant difference between the two groups. According to Mann-Whitney U-test, there was no significant difference between the experimental and control groups in terms of patients' educational levels $(\mathrm{P}=0.71)$ (Table 2).

The independent $\mathrm{t}$-test indicated that there was no significant differ- ence between the two groups in terms of the mean scores of quality of life and its dimensions before the intervention $(\mathrm{P}>0.05)$, but the mean score of quality of life and its dimensions was significantly greater in the experimental group than that in the control group after the intervention $(\mathrm{P}<0.001)$. According to the paired $\mathrm{t}$-test, the mean score of quality of life and its dimensions was significantly higher in the experi- 
mental group after the intervention than before the intervention $(\mathrm{P}<0.001)$. The paired t-test indicated that there was no significant difference between the mean scores of quality of life and its dimensions in the control group before and after the intervention $(\mathrm{P}>0.05)$ (Table 3).

Table 4 presents the results of frequency of response to each question of quality of life questionnaire before and after the intervention in both the experimental and control groups. After applying the continuous care model, the experimental group's response resulted in a remarkable change in the sensitivity to lower extremity edema; improved shortness of breath; resolved problems with walking, communicating with friends and relatives, allocating a special time for exercise and physical activity, and not being readmitted at the hospital; improved sensory and decentralization disorder; and absence of discomfort, worry, and depression (Table 4).

\section{DISCUSSION}

The present study was conducted on 72 patients diagnosed with heart failure who were hospitalized at Shahid Chamran Hospital of Isfahan. Patients were randomly divided into the experimental and control groups (36 patients per group). Results of demographic variables indicated that there was no significant difference between the demographic variables such as age, sex, marital status, and educational level in both the control and experimental groups. In fact, the frequency distribution of sex, age, marital status, and educational level was similar between the experimental and control groups, but the variables had no confounding effect on this intervention.

Results of the present study indicated that the mean score of quality of life in the experimental group was significantly higher than that in the control group after the intervention based on the continuous care model. In fact, the patients' quality of life significantly improved after the intervention, compared to before the intervention with the implementation of the continuous care model in the experimental group, but the patients' quality of life did not significantly change in the control group.

Considering that the model paid attention to all effective factors including physical activity, dietary regimen, medication regimen, lifestyle change, and late and early complications of disease on the quality of life and due to the continuous sensitization process at all stages, the scores of dimensions of quality of life significantly increased in different dimensions.

Consistent with the present study, West et al. ${ }^{21)}$ implemented a 24hour nursing program including education, counseling, control, and follow-up and reported that patients' quality of life significantly improved in, both, physical and psychological dimensions.

Furthermore, Harrison et al. ${ }^{18)}$ compared the two models of routine and continuous patient care and reported that their scores of quality of life were significantly higher in patients with continuous care compared to patients receiving routine care 6 months after discharge.

Rodriguez et al ${ }^{22)}$ stated that training patients with heart failure was the basis of their self-care. In this regard, it is significantly important to understand the patients' clinical and individual perception and experience. Most patients are aware of the importance of self-care that significantly affects their quality of life and daily activities.

Baghaei et al. ${ }^{23)}$ indicated that the patients' quality of life significantly increased in all dimensions by implementing the continuous care model over 3 months $(\mathrm{P}<0.001)$.

In a study by Evangelista et al., ${ }^{24)}$ who examined the impact of continuous care counseling in 36 ambulatory patients with heart failure after discharge, the findings indicated that continuous care counseling improved stress, depressive symptoms, and patients' quality of life after discharge.

In a paper titled "The continuous care of ambulatory patients suffering from chronic heart failure," Bekelman et al. ${ }^{25)}$ indicated that the continuous care increased the clinical management of disease and coordination of care for patients and their families, thereby improving the patients' quality of life.

In this regard, a clinical trial study by Gelfman et al. ${ }^{26)}$ included telephone interviews with 149 family members of patients to evaluate the quality of health care in patients. Among them, 54 patients received continuous care and 95 received routine care. A total of $65 \%$ of family members of patients, who received continuous care, reported positive feelings and emotional needs.

The most important difference between our study and the abovementioned studies is the strategy applied in training sessions. In the current study, we have determined behavioral goals and educational strategies according to the following three different domains: cognitive, affective, and psychomotor. This strategy results in the segmentation in delivering educational material and the better understanding of patient regarding the importance of different dimensions of lifestyle.

In explaining these findings, it can be concluded that continuous care after discharge is an important strategy for controlling disease and the key to success of treatment. In a more detailed view, the results of the present study indicated that patients did not pay sufficient attention to issues such as maintaining and controlling weight, performing physical activity, sleeping problems, reasons for excessive fatigue and reduced energy, controlling discomfort and stress, taking medication according to the physician's prescription, and non-attention to symptoms of disease recurrence such as shortness of breath, increased leg or ankle swelling, and increased fatigue before the implementation of continuous care model. However, a significant percentage of these patients gained the necessary knowledge and attitude on these issues after implementing this model. In fact, the model was able to significantly affect patients' lifestyle changes in terms of important factors such as nutrition, physical activity, and drug use.

The results of the present study indicated that the highest score was in the emotional dimension in terms of different aspects of lifestyle after the implementation of the continuous care model. The present study indicated that continuous counseling programs improved the satisfaction of patients' family members through attention to family.

According to the findings of the present study, the least improve- 
ment was associated with the general dimension of quality of life, and this finding seemed reasonable since the continuous care of study was more focused on physical and emotional dimensions.

\section{Strength and Limitation}

Conducting a follow-up study using an appropriate framework in improving the quality of life of patients with heart failure is the strength of the current study. Considering that this is a pilot, single-center study, the results of this study may not be generalized to other patients and territories. This issue has been considered as the main limitation of this study.

\section{Conclusion}

The results of the present study indicated that planned telephone follow-up significantly increased patients' mean scores of quality of life. Therefore, post-discharge follow-up was a factor contributing to the improvement of quality of life. Considering the increased incidence of heart failure in all societies, it is necessary to perform effective interventions to improve the quality of life of these patients to prevent their disability and life limitations. Finally, it can be concluded that applying a continuous care model in other clinical spaces and patients with heart failure can have successful results, and it can be used to improve the quality of life of patients diagnosed with other chronic diseases.

\section{CONFLICT OF INTEREST}

No potential conflict of interest relevant to this article was reported.

\section{ORCID}

Fatemeh Rezamand: https://orcid.org/0000-0001-9518-1761

Hossein Shahnazi: https://orcid.org/0000-0002-5901-3901

Akbar Hassanzadeh: https://orcid.org/0000-0002-4555-0992

\section{REFERENCES}

1. Bagherian-Sararoudi R, Maracy M, Sanei H, Shiri M. Factors in relation with fatigue and illness perception in patients with myocardial infarction and the changes in fatigue due to intervention on illness perception: research design, methodology, and preliminary results. ARYA Atheroscler 2019;15:74-81.

2. Sadeghi Akbari A, Cheraghi MA, Kazemnejad A, Nomali M, Zakerimoghadam M. Effect of illness perception correction-based educational program on quality of life and self-care in patients with heart failure: a randomized controlled trial. J Caring Sci 2019;8:89-93.

3. Thulasimani M, Ramaswamy M. Suggestions to improve the quality of life in heart failure. Eur Heart J 2003;24:1700.

4. Hadaegh F, Harati H, Ghanbarian A, Azizi F. Prevalence of coronary heart disease among Tehran adults: Tehran lipid and glucose study. East Mediterr Health J 2009;15:157-66.

5. Xuan J, Duong PT, Russo PA, Lacey MJ, Wong B. The economic burden of congestive heart failure in a managed care population. Am J Manag
Care 2000;6:693-700.

6. Wu JR, Chung M, Lennie TA, Hall LA, Moser DK. Testing the psychometric properties of the Medication Adherence Scale in patients with heart failure. Heart Lung 2008;37:334-43.

7. Annema C, Luttik ML, Jaarsma T. Reasons for readmission in heart failure: perspectives of patients, caregivers, cardiologists, and heart failure nurses. Heart Lung 2009;38:427-34.

8. Comin-Colet J, Lainscak M, Dickstein K, Filippatos GS, Johnson P, Luscher TF, et al. The effect of intravenous ferric carboxymaltose on health-related quality of life in patients with chronic heart failure and iron deficiency: a subanalysis of the FAIR-HF study. Eur Heart J 2013; 34:30-8.

9. Kinney MR. Quality of life research: rigor or rigor mortis. Cardiovasc Nurs 1995;31:25-8.

10. The World Health Organization Quality of Life assessment (WHOQOL): position paper from the World Health Organization. Soc Sci Med 1995;41:1403-9.

11. Paul S. Hospital discharge education for patients with heart failure: what really works and what is the evidence? Crit Care Nurse 2008;28: 66-82.

12. Seto E. Cost comparison between telemonitoring and usual care of heart failure: a systematic review. Telemed J E Health 2008;14:679-86.

13. Mistiaen P, Poot E. Telephone follow-up, initiated by a hospital-based health professional, for postdischarge problems in patients discharged from hospital to home. Cochrane Database Syst Rev 2006;2006: CD004510.

14. Clark RA, Inglis SC, McAlister FA, Cleland JG, Stewart S. Telemonitoring or structured telephone support programmes for patients with chronic heart failure: systematic review and meta-analysis. BMJ 2007;334:942.

15. Abedi H, Arefi S, Ahmadi F, Faghihi-Zadeh S, Ghofranipour F. Effect of continuous consultation care model on re hospitalization and chest pain in patients with coronary artery disease. J Qazvin Univ Med Sci, 2005;35:99-103.

16. Poorgholami F, Mansoori P, Montaseri Z, Najafi K. Effect of self care education with and without telephone follow-up on the level of hope in renal dialysis patients: a single-blind randomized controlled clinical trial. Int J Community Based Nurs Midwifery 2016;4:256-64.

17. Razmjoee N, Ebadi A, Asadi-Lari M, Hosseini M. Does a "continuous care model" affect the quality of life of patients undergoing coronary artery bypass grafting? J Vasc Nurs 2017;35:21-6.

18. Harrison MB, Browne GB, Roberts J, Tugwell P, Gafni A, Graham ID. Quality of life of individuals with heart failure: a randomized trial of the effectiveness of two models of hospital-to-home transition. Med Care 2002;40:271-82.

19. Jaarsma T, Halfens R, Tan F, Abu-Saad HH, Dracup K, Diederiks J. Selfcare and quality of life in patients with advanced heart failure: the effect of a supportive educational intervention. Heart Lung 2000;29:31930.

20. Rector TS, Cohn JN. Assessment of patient outcome with the Minnesota Living with Heart Failure Questionnaire: reliability and validity during a randomized, double-blind, placebo-controlled trial of pimobendan. Pimobendan Multicenter Research Group. Am Heart J 1992; 124:1017-25.

21. West JA, Miller NH, Parker KM, Senneca D, Ghandour G, Clark M, et 
al. A comprehensive management system for heart failure improves clinical outcomes and reduces medical resource utilization. Am J Cardiol 1997;79:58-63.

22. Rodriguez KL, Appelt CJ, Switzer GE, Sonel AF, Arnold RM. “They diagnosed bad heart": a qualitative exploration of patients' knowledge about and experiences with heart failure. Heart Lung 2008;37:257-65.

23. Baghaei R, mashallahi a, khalkhali $\mathrm{H}$. The effect of applying continuous care model on the quality of life in heart failure patients. J Urmia Nurs Midwifery Fac 2015;13:666-75.

24. Evangelista LS, Lombardo D, Malik S, Ballard-Hernandez J, Motie M,
Liao S. Examining the effects of an outpatient palliative care consultation on symptom burden, depression, and quality of life in patients with symptomatic heart failure. J Card Fail 2012;18:894-9.

25. Bekelman DB, Nowels CT, Allen LA, Shakar S, Kutner JS, Matlock DD. Outpatient palliative care for chronic heart failure: a case series. J Palliat Med 2011;14:815-21.

26. Gelfman LP, Meier DE, Morrison RS. Does palliative care improve quality?: a survey of bereaved family members. J Pain Symptom Manage 2008;36:22-8. 